\title{
Thermodynamic Study of the Solubility of Some Sulfonamides in Cyclohexane
}

\author{
Fleming Martínez $z^{*, a}$, Carolina M. Ávila ${ }^{a}$ and Alfredo Gómez ${ }^{b}$ \\ ${ }^{a}$ Departamento de Farmacia, Universidad Nacional de Colombia, A.A. 14490, Bogotá D.C., Colombia \\ ${ }^{b}$ Departamento de Química, Universidad Nacional de Colombia, A.A. 14490, Bogotá D.C., Colombia
}

\begin{abstract}
As variações nas funções termodinâmicas energia de Gibbs, entalpia e entropia para os processos de solução de uma série de sulfonamidas em cicloexano foram determinadas nas temperaturas de 20,0 a $40,0^{\circ} \mathrm{C}$. A energia de Gibbs de excesso e os coeficientes de atividade destes solutos também foram calculados. Estes resultados são discutidos em termos de interações soluto-solvente nestes sistemas.
\end{abstract}

The thermodynamic functions Gibbs energy, enthalpy and entropy of solution in cyclohexane, were evaluated from solubility data for a group of sulfonamides over the temperature range from 20.0 to $40.0{ }^{\circ} \mathrm{C}$. The excess Gibbs energy and the activity coefficients of the solutes were also determined. The results are discussed in terms of solute-solvent interactions.

Keywords: sulfonamides, solubility, solution thermodynamics, activity coefficient, cyclohexane

\section{Introduction}

Sulfonamides are drugs extensively used for the treatment of certain infections caused by gram-positive and gram-negative microorganisms, some fungi, and certain protozoa. Several physical and chemical parameters of these compounds have been correlated with their chemotherapeutic activity: $\mathrm{pK}_{\mathrm{a}}$, protein binding, and electronic charge distribution, among others. Unfortunately, no single parameter can explain the action of sulfonamides. ${ }^{1}$ The information known so far does not allow the proposition of suitable mechanisms for the process of transfer of sulfonamides between immiscible liquid phases or between aqueous media and biological membrane models, which would explain their differences in biological activity as a function of their molecular structure. However, the temperature dependence of the solubility may be used to account for these differences. ${ }^{2}$

Mauger et $\mathrm{al}^{3}{ }^{3}$ have determined the solubility of sulfadiazine, sulfisomidine, sulfadimethoxine, and sulfisoxazole in some alcohols at 25,30 , and $37^{\circ} \mathrm{C}$, while Regosz et al.,$^{4}$ have evaluated the aqueous solubility of a variety of sulfonamides at several temperatures. Martínez and Gómez ${ }^{5}$ have studied the thermodynamics of solution

\footnotetext{
* e-mail: fmartine@ ciencias.unal.edu.co
}

of some sulfonamides in octanol, water, and the mutually saturated solvents.

In order to have systematic and more complete physicochemical information about the transfer of sulfonamides between aqueous and organic phases, in this work the solubility of eight structurally related sulfonamides in cyclohexane was determined at several temperatures, and the related thermodynamic functions were calculated. Cyclohexane and octanol have been used as standard organic media for partitioning experiments in the study of quantitative structure-activity relationships (QSAR). Cyclohexane is a non-polar lipophilic hydrocarbon solvent, and therefore it is used in the evaluation of hydrophobic interactions. ${ }^{6}$ The theoretical thermodynamic aspects of the solubility of solid solutes have been discussed elsewhere. ${ }^{3,5,7}$

\section{Experimental}

\section{Materials}

Sulfanilamide (SA) Merck; sulfapyridine (SP), sulfadiazine (SD), sulfamerazine (SMR), sulfamethazine (SMT) Sigma Chemical Co.; sulfacetamide (SCM), sulfathiazole (STL), sulfamethoxazole (SMX) USP Quality. ${ }^{8}$ Cyclohexane A.R. Merck; distilled water, conductivity $<2 \mu \mathrm{S}$, Laboratory of Industrial Pharmacy; hydrochloric acid A.R., sodium nitrite A.R., ammonium 
sulfamate A.R., N-(1-naphtyl)-ethylenediamine hydrochloride A.R., Merck; indium DSC standard; Millipore Corp. Swinnex ${ }^{\circledR}-13$ filter units.

\section{Equipment}

Magni Whirl Blue M. Electric Company water baths; Wrist Action, Burrel, model 75 mechanical shaker; Mettler AE 160 and Sartorius K200D digital analytical balances, sensitivities of $0.1 \mathrm{mg}$ and $0.01 \mathrm{mg}$, respectively; Buchler Rotational Evaporator; DMA45 Anton Paar digital density meter; Unicam UV-Vis UV2-100 v 4.00 spectrophotometer; 2910 Modulated DSC, TA Instruments differential scanning calorimeter; Nichiryo ${ }^{\circledR}$ micro pipettes.

\section{Methods}

Calorimetric studies. Determination of melting points, enthalpies of fusion, and purity analysis were performed by differential scanning calorimetry (DSC). All measurements were carried out at a heating rate of $10{ }^{\circ} \mathrm{C} \mathrm{min}^{-1}$ in a dynamic nitrogen atmosphere $\left(50 \mathrm{~mL} \mathrm{~min}{ }^{-1}\right)$. About $4 \mathrm{mg}$ of each sulfonamide was used. The equipment was calibrated using indium as standard. ${ }^{9}$ All thermal analyses were carried out at least three times.

Solubility determinations. About $100 \mathrm{mg}$ of each sulfonamide (an excess of substance) were added to 100 $\mathrm{mL}$ of cyclohexane in glass flasks. The mixtures were stirred in a mechanical shaker for 1 hour. Samples were then allowed to stand in water baths kept at the appropriate temperature $\pm 0.1^{\circ} \mathrm{C}$, for at least 30 days. After, the solutions were filtered to ensure that they were free of particulate matter before sampling. The solvent was removed from the solutions (aliquots of $50 \mathrm{~mL}$ ) in a rotatory evaporator. This procedure was carried out due to the low solubility of these compounds in this aprotic solvent (about $100 \mathrm{ng}$ $\mathrm{mL}^{-1}$ ), compared with those obtained in water or octanol. The amount of dissolved sulfonamides was determined by the method previously proposed by Bratton et al., ${ }^{7,10}$ modified as follows: $0.250 \mathrm{~mL}$ of water and $0.250 \mathrm{~mL}$ of $50 \%(\mathrm{v} / \mathrm{v}) \mathrm{HCl}$ were added to the flasks that contained the sulfonamides, followed by $0.125 \mathrm{~mL}$ of $0.1 \%$ sodium nitrite. The mixture was stirred and allowed to stand for three min. After this time $0.125 \mathrm{~mL}$ of $0.5 \%$ ammonium sulfamate were added, and the solution was allowed to stand for two more min. Finally, $0.250 \mathrm{~mL}$ of $0.1 \% \mathrm{~N}-(1-$ naphtyl)-ethylenediamine hydrochloride, were added to form the red azo-derivative. All solutions were allowed to stand for $15 \mathrm{~min}$ and the readings at the specific $\lambda_{\text {max }}$ were taken in polypropylene cells. All solubility experiments were repeated at least three times.

\section{Results and Discussion}

The molecular structures of the studied sulfonamides, in addition to their molar masses, and the $\lambda_{\max }$ values for the azo-derivatives in water, are summarized in Table 1.

Table 1. Some chemical properties of the studied sulfonamides

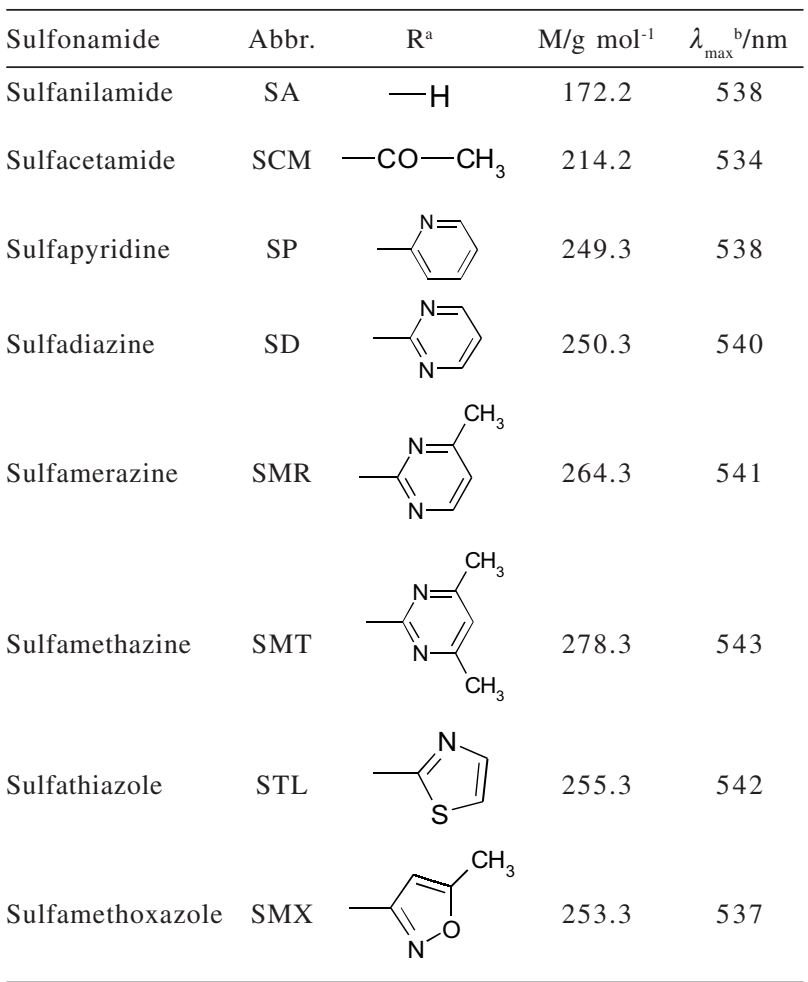

a Substituent on the basic structure of sulfanilamide:

$\mathrm{H}_{2} \mathrm{~N}-\mathrm{SO}_{2}-\mathrm{NHR}$

${ }^{\mathrm{b}}$ Obtained as the azo-derivative in water.

\section{Ideal solubility}

The ideal solubility of a crystalline solute in a liquid solvent can be calculated by equation 1 :

$\ln x_{2}{ }^{i}=-\frac{\Delta_{\text {fus }} H\left(T_{\text {fus }}-T\right)}{R T_{\text {fus }} T}+\left(\frac{\Delta C_{p}}{R}\right)\left[\frac{\left(T_{\text {fus }}-T\right)}{T}+\ln \left(\frac{T}{T_{\text {fus }}}\right)\right]$

where $x_{2}{ }^{i}$ is the ideal solubility of the solute as mole fraction, $\Delta_{\text {fus }} H$ is the molar enthalpy of fusion of the pure solute (at the melting point), $T_{\text {fus }}$ is the absolute melting point, $T$ is the absolute solution temperature, $R$ is the gas constant, and $\Delta C_{p}$ is the difference between the molar heat capacity of the crystalline form and the molar heat capacity of the hypothetical supercooled liquid form, both at the solution temperature. ${ }^{11}$ 
Table 2. Melting points, enthalpies of fusion ( \pm s. d.), entropies of fusion ( \pm s. d.), and ideal solubilities of sulfonamides (in mole fraction)

\begin{tabular}{|c|c|c|c|c|c|c|}
\hline \multirow[t]{2}{*}{ Compound } & \multirow{2}{*}{$T_{\text {fus }} /{ }^{\circ} \mathrm{C}$} & \multirow{2}{*}{$\Delta_{f u s} H / \mathrm{kJ} \mathrm{mol}^{-1}$} & \multirow{2}{*}{$\Delta_{f u s} S / \mathrm{J} \mathrm{mol}^{-1} \mathrm{~K}^{-1}$} & \multicolumn{3}{|c|}{ Ideal solubility / $\left(10^{-4}\right)$} \\
\hline & & & & $25.0^{\circ} \mathrm{C}$ & $30.0^{\circ} \mathrm{C}$ & $40.0^{\circ} \mathrm{C}$ \\
\hline SA & 162.2 & $23.3(0.8)$ & $53.5(1.8)$ & 519 & 605 & 813 \\
\hline SCM & 182.0 & $29.8(0.4)$ & $65.4(0.9)$ & 159 & 194 & 283 \\
\hline SP & 189.5 & $40.47(0.14)$ & $87.48(0.30)$ & 301 & 39.4 & 65.8 \\
\hline SD & 259.5 & $44.3(0.4)$ & $83.1(0.7)$ & 3.86 & 5.18 & 9.08 \\
\hline SMR & 235.3 & $41.3(1.0)$ & $81.2(1.9)$ & 10.2 & 13.4 & 22.7 \\
\hline SMT & 195.8 & $39.2(0.7)$ & $83.6(1.5)$ & 31.4 & 40.8 & 67.0 \\
\hline STL & 199.8 & $30.3(1.0)$ & $64.0(2.1)$ & 110 & 134 & 197 \\
\hline SMX & 167.5 & $33.76(0.25)$ & $76.6(0.6)$ & 122 & 153 & 235 \\
\hline
\end{tabular}

Since $\Delta C_{p}$ cannot be easy experimentally determined, one of the following assumptions has to be made: (a) $\Delta C_{p}$ is negligible and can be considered zero or (b) $\Delta C_{p}$ may be approximated to the entropy of fusion, $\Delta_{\text {fus }} S$. The simplified equation is:

$\ln x_{2}^{i}=-\frac{\Delta_{f u s} H\left(T_{\text {fus }}-T\right)}{R T_{\text {fus }} T}$

Table 2 summarizes the determined DSC results and the ideal solubilities (equation 2) of all studied sulfonamides. All $T_{\text {fus }}$ values are in good agreement with those reported in the literature. ${ }^{12}$ There are only a few values of enthalpy and entropy of fusion reported in the literature, and they have been obtained by differential thermal analysis (DTA), a semiquantitative method, while the values presented here were obtained by DSC, a quantitative method, the latter being more appropriate for the determination of molar enthalpies of fusion. Our values are generally greater than those reported by Yang and Guillory, ${ }^{13}$ and Sunwoo and Eisen, ${ }^{14}$ but for SD and SMR, they are very similar to those reported by Maury et al. ${ }^{15}$

Since the ideal solubility depends on the melting point and the enthalpy of fusion, it is important to know how these properties vary among the various sulfonamides. From Table 2 it can be seen that $T_{\text {fus }}$ decreases in the order SD $>$ SMR $>$ STL $>$ SMT $>$ SP $>$ SCM $>$ SMX $>$ SA, and that the enthalpy of fusion decreases in the order $\mathrm{SD}>\mathrm{SMR}>$ SP $>$ SMT $>$ SMX $>$ STL $>$ SCM $>$ SA. The enthalpy of fusion may be considered as the heat required to increase the intermolecular distances in crystals, allowing melting to occur. A crystal where the molecules are bound by weak forces generally has a low heat of fusion and a low melting point, whereas one bound by strong forces has a high heat of fusion and a high melting point. The forces involved are mainly hydrogen bond and van der Waals interactions, which depend on molecular size and some geometric parameters. ${ }^{16}$ Unlike other pharmaceutical compounds such as barbiturates, parabens, and substituted phenols, these sulfonamides do not constitute a homologous series. Thus, the magnitudes of the physicochemical properties for each solute must be regarded only in terms of relative substituent effects.

The ideal solubility $\left(x_{2}{ }^{i}\right)$ is inversely proportional to the enthalpy of fusion (equation 2), therefore, it is expected to follow the same sequence of $x_{2}^{i}$ : $\mathrm{SA}>\mathrm{SCM}>\mathrm{SMX}>$ STL $>$ SMT $>$ SP $>$ SMR $>$ SD, which is almost the inverse order of the determined enthalpies of fusion: $\mathrm{SA}<\mathrm{SCM}<$ $\mathrm{STL}<\mathrm{SMX}<\mathrm{SMT}<\mathrm{SP}<\mathrm{SMR}<\mathrm{SD}$.

\section{Experimental solubility of sulfonamides}

Table 3 summarizes the experimental solubilities expressed as mole fractions. These values are lower than those obtained in other solvents used in QSAR studies, such as water or octanol. ${ }^{5,7}$

Table 3. Experimental solubility in mole fraction of sulfonamides as a function of temperature $\left( \pm 0.1{ }^{\circ} \mathrm{C}\right)$

\begin{tabular}{ccccr}
\hline Compd. & \multicolumn{4}{c}{ Mole fraction / $\left(10^{-8}\right)$} \\
& $20.0{ }^{\circ} \mathrm{C}$ & $25.0{ }^{\circ} \mathrm{C}^{\mathrm{a}}$ & $30.0{ }^{\circ} \mathrm{C}$ & $40.0{ }^{\circ} \mathrm{C}$ \\
\hline SA & $1.16(0.16)$ & 1.64 & $2.32(0.16)$ & $4.10(0.14)$ \\
SCM & $1.86(0.18)$ & 2.78 & $4.1(0.6)$ & $8.3(0.3)$ \\
SP & $5.0(1.2)$ & 7.16 & $10.3(1.3)$ & $19.5(2.1)$ \\
SD & $0.63(0.04)$ & 0.845 & $1.15(0.14)$ & $1.8(0.4)$ \\
SMR & $3.90(0.13)$ & 5.55 & $7.5(0.4)$ & $17.3(2.2)$ \\
SMT & $27.8(1.5)$ & 41.6 & $63.5(2.5)$ & $116.4(2.9)$ \\
STL & $1.15(0.09)$ & 1.39 & $1.70(0.12)$ & $2.22(0.04)$ \\
SMX & $10.5(2.2)$ & 14.8 & $21.0(3.2)$ & $36.9(1.6)$ \\
\hline
\end{tabular}

${ }^{a}$ Calculated from van't Hoff plots.

The experimental solubility decreases in the order SMT $>\mathrm{SMX}>\mathrm{SP}>\mathrm{SMR}>\mathrm{SCM}>\mathrm{SA}>\mathrm{STL}>\mathrm{SD}$, which is different than that for the ideal solubility. The sequence for the experimental solubilities is almost the same of partial molar volumes at infinite dilution in the $(x=0.5)$ water-ethanol mixture (the volume decreases in the order SMT $>$ SMX $>$ SP $>$ SA $>$ SMR $>$ SD $>$ SCM $>$ STL $).{ }^{17}$ The main type of interaction that exists between sulfonamides 
and cyclohexane is hydrophobic, therefore the solubility depends on the contact between the solute and solvent molecules, in addition to $T_{\text {fus }}$ and $\Delta_{\text {fus }} H$; hence, the solubility should be greater as the size of the molecule increases. ${ }^{18}$ The above assumption has been evaluated by studying the molecular surface areas and the calculated molecular volumes, as has been done for other pharmaceutical compounds including some sulfonamides. ${ }^{19}$ Molecular surface areas (MSA) and molecular volumes (MV) of the sulfonamides studied calculated by means of CODESSA ${ }^{20}$ are presented in Table 4. This computer program calculates MSA and MV from atomic contributions as Bondi's van der Waals spheres. ${ }^{21}$ All calculations were performed on molecular geometry optimized by molecular mechanics (MM+). It can be seen in Table 4 that MSA and MV decrease in the order $\mathrm{SMT}>\mathrm{SMR}>\mathrm{SP}>\mathrm{SD}>\mathrm{SMX}>\mathrm{STL}>\mathrm{SCM}$ $>\mathrm{SA}$, which is different from that of solubility in cyclohexane. A simple relationship between solubility and MSA or MV was not found for these sulfonamides; therefore the solubility of these compounds in cyclohexane is more complex than what could be expected from simple models of solubility.

Table 4. Molecular surface areas (MSA) and molecular volumes (MV) of sulfonamides calculated by means of CODESSA

\begin{tabular}{ccc}
\hline Compd. & MSA/ $^{2}$ & ${\mathrm{MV} / \AA^{3}}^{3}$ \\
\hline SA & 198.23 & 170.68 \\
SCM & 247.70 & 219.54 \\
SP & 276.03 & 240.41 \\
SD & 269.18 & 236.44 \\
SMR & 281.55 & 250.95 \\
SMT & 303.23 & 267.77 \\
STL & 260.22 & 229.37 \\
SMX & 265.94 & 235.21 \\
\hline
\end{tabular}

In order to facilitate the analysis, Table 5 summarizes the solubility ratio of the other compounds with respect to the least soluble compound, SD.
Table 5. Solubility ratio related to sulfadiazine at $25.0 \pm 0.1{ }^{\circ} \mathrm{C}$ (in mole fraction)

\begin{tabular}{crc}
\hline Compd. & Ideal & Cyclohexane \\
\hline SA & 134.3 & 1.9 \\
SCM & 41.2 & 3.3 \\
SP & 7.8 & 8.5 \\
SD & 1.0 & 1.0 \\
SMR & 2.6 & 6.6 \\
SMT & 8.1 & 49.3 \\
STL & 28.4 & 1.7 \\
SMX & 31.7 & 17.5 \\
\hline
\end{tabular}

\section{Thermodynamic functions of solution}

The Gibbs energy, the enthalpy, and the entropy of solution were calculated by means of equations 3,4 , and 5 :

$$
\begin{aligned}
& \Delta_{s o l} G=-R T \ln x_{2} \\
& {\left[\frac{\partial\left(-\ln x_{2}\right)}{\partial(1 / T)}\right]_{p}=\frac{\Delta_{s o l} H}{R}} \\
& \Delta_{s o l} G=\Delta_{s o l} H-T \Delta_{s o l} S
\end{aligned}
$$

Table 6 summarizes the thermodynamic functions of solution process in cyclohexane. These values were calculated from the solubilities presented in Table 3 by means of Gibbs and van't Hoff equations using weighed values and errors propagation methods. ${ }^{22}$ Straight lines with correlation coefficients ( $r$ ) greater than 0.95 were obtained in all solubility analyses by the van't Hoff method, therefore the enthalpies of solution may be calculated from the slopes following equation 4 .

It is found that the standard Gibbs energy of solution is positive in all cases, that is, the solution process is not spontaneous. The enthalpy of solution is positive in all cases, therefore this process is always endothermic. The entropy of solution is positive for all solutes, except for SD and STL.

Table 6. Thermodynamic functions for the solution process of sulfonamides in cyclohexane $\left(\Delta S\right.$ and $\Delta G$ at $\left.25.0 \pm 0.1{ }^{\circ} \mathrm{C}\right)$

\begin{tabular}{cccccccc}
\hline Compd. & \multicolumn{2}{c}{ Enthalpy / $\mathrm{kJ} \mathrm{mol}^{-1}$} & \multicolumn{2}{c}{ Entropy / J mol ${ }^{-1} \mathrm{~K}^{-1}$} & \multicolumn{3}{c}{ Gibbs energy / kJ mol ${ }^{-1}$} \\
& $\Delta_{\text {sol }} H$ & $\Delta_{m i x} H$ & $\Delta_{\text {sol }} S$ & $\Delta_{m i x} S$ & $\Delta_{\text {sol }} G$ & $\Delta_{\text {sol }} G^{\mathrm{i}}$ & $\Delta_{\text {sol }} G^{\mathrm{E}}$ \\
\hline SA & 48.2 & 25.0 & 12.7 & -40.8 & 44.4 & 7.33 \\
SCM & 57.3 & 27.5 & 47.5 & -18.0 & 43.1 & 10.3 & 37.1 \\
SP & 52.2 & 11.7 & 38 & -49 & 40.8 & 14.4 & 26.4 \\
SD & 39.3 & -5.0 & -23 & -106 & 46.1 & 19.5 & 26.6 \\
SMR & 56.8 & 15.5 & 52 & -30 & 41.4 & 17.1 & 24.3 \\
SMT & 54.8 & 15.5 & 61.5 & -22.1 & 36.4 & 14.3 & 22.1 \\
STL & 25.0 & -5.2 & -66.5 & -130.5 & 44.8 & 11.2 & 33.7 \\
SMX & 48.0 & 14.3 & 30 & -46 & 39.0 & 10.9 & 28.1 \\
\hline
\end{tabular}




\section{Thermodynamic functions of mixing}

For the non-ideal case, the solubility process can be approximately described by the following hypothetic process:

Solute $_{\text {(solid) }} \rightarrow$ Solute $_{\text {(liquid) }} \rightarrow$ Solute $_{\text {(solution) }}$

The above scheme has two steps: the melting of solute and its mixing with the solvent. Therefore, the functions enthalpy $\left(\Delta_{\text {mix }} H\right)$ and entropy $\left(\Delta_{\text {mix }} S\right)$ of mixing can be calculated from the enthalpy $\left(\Delta_{\text {fus }} H\right)$ and entropy $\left(\Delta_{f u s} S\right)$ of fusion that are determined experimentally (assuming that these properties do not change with temperature), and from the enthalpy $\left(\Delta_{\text {sol }} H\right)$ and entropy $\left(\Delta_{\text {sol }} S\right)$ of solution, by means of equations 6,7 , and 8 , respectively. ${ }^{3,5}$

$\Delta_{s o l} G^{\mathrm{E}}=\Delta_{s o l} G-\Delta_{s o l} G^{\mathrm{i}}$

$\Delta_{\text {sol }} H=\Delta_{\text {fus }} H+\Delta_{\text {mix }} H$

$\Delta_{\text {sol }} S=\Delta_{\text {fus }} S+\Delta_{\text {mix }} S$

The calculation of $\Delta_{f u s} H$ and $\Delta_{\text {fus }} S$ from the data of Table 6 indicates that these parameters are always positive, while the contribution of the mixing process to solution is variable; that is, $\Delta_{m i x} H$ is negative for SD and STL, while it is positive for all other sulfonamides. The entropy of mixing $\left(\Delta_{m i x} S\right)$ is negative for all sulfonamides. It can be concluded that the process of solution is driven mainly by the entropy of solution and by the enthalpy of mixing, except for SD and STL.

The negative values of $\Delta_{m i x} S$ suggest some type of structure formation in cyclohexane, nevertheless, it is not easy to identify the possible solute-solvent or solventsolvent interactions that may explain the respective entropy decrease, whereas in water or octanol the main interaction is by hydrogen bonding. 5,7

\section{Activity coefficients}

The activity coefficients $\left(\gamma_{2}\right)$ calculated by means of equation 9 from the solubility data in Tables 2 and 3 are presented in Table 7.

$\gamma_{2}=x_{2}^{i} / x_{2}$

These values allow a rough estimate of the intermolecular interactions between solutes and solvent by means of equation 10 :

$\ln \gamma_{2}=\left(w_{11}+w_{22}-2 w_{12}\right) \frac{V_{2} \phi_{1}^{2}}{R T}$ where $w_{11}, w_{22}$ and $w_{12}$ represent the solvent-solvent, solutesolute and solvent-solute interaction energies, respectively; $V_{2}$ is the molar volume of the subcooled liquid solute, and $\phi_{1}$ is the volume fraction of the solvent. The term $\left(V_{2} \phi_{1}{ }^{2} /\right.$ $R T$ ) may be considered constant at the same temperature, then $\gamma_{2}$ depends almost exclusively on $w_{11}, w_{22}$ and $w_{12}{ }^{23}$

Table 7. Activity coefficients of solutes in cyclohexane as a function of temperature $\left( \pm 0.1{ }^{\circ} \mathrm{C}\right)$

\begin{tabular}{cccc}
\hline Compd. & \multicolumn{3}{c}{$\gamma_{2} /\left(10^{3}\right)$} \\
& 25.0 & 30.0 & 40.0 \\
\hline SA & 3170 & 2610 & 1980 \\
SCM & 566 & 471 & 339 \\
SP & 42.0 & 38.2 & 33.8 \\
SD & 45.7 & 45.2 & 51.5 \\
SMR & 18.4 & 17.9 & 11.3 \\
SMT & 7.54 & 6.42 & 5.76 \\
STL & 789 & 791 & 889 \\
SMX & 82.6 & 73.0 & 63.6 \\
\hline
\end{tabular}

It can be seen in equation 10 that the contribution of $w_{22}$ is constant for each sulfonamide, since it represents the work necessary to take a molecule to the vapor state. The greater $\gamma_{2}$ values in cyclohexane (close to $10^{6}$ ) compared with those obtained in octanol, water or mutually saturated solvents, ${ }^{5}$ which are hydrogen bonding solvents (close to $10^{3}$ ), indicate that the contribution of $w_{11}$ in cyclohexane (aprotic solvent) is lower, hence the $w_{12}$ values (relative to solute-solvent interactions) are also very small.

From activity coefficients, the "ideal" mixing behavior decreases in the $\mathrm{SMT}>\mathrm{SMR}>\mathrm{SP}>\mathrm{SMX}>\mathrm{SCM}>\mathrm{STL}>$ SA. On the other hand, for SA, SCM, SP, SMR, and SMT, $\gamma_{2}$ decreases with the increase in temperature, whereas for SD and STL, $\gamma_{2}$ increases with the increase in temperature. It is important to note that for SD and STL, the enthalpy of mixing $\left(\Delta_{m i x} H\right)$ is negative, while it is positive for the rest of sulfonamides (Table 6). Therefore, it may be concluded that if $\Delta_{\text {mix }} H$ is positive, $\gamma$ decreases with the increase of temperature, or the solution process tends to be more ideal.

\section{Conclusions}

The previous analysis allows to conclude that the solubilities of sulfonamides in cyclohexane are low compared with those obtained in other solvents such as alcohols or water, ${ }^{3-5}$ therefore, the activity coefficients in cyclohexane are greater, in the order of $10^{6}$, showing nonideal behavior in this solvent. These solubility data along with other literature data ${ }^{4,5}$ allow estimates of partition coefficients for these solutes in cyclohexane/water system. ${ }^{24}$ These values are important for comparison with 
other standard partitioning systems like octanol/water, and for further QSAR studies. ${ }^{6,7,25}$

\section{Acknowledgments}

We thank Banco de la República and Merck Colombia S.A. for the financial support and for providing the cyclohexane, respectively. Also we thank the Departments of Pharmacy, Chemistry, and Chemical Engineering of the Universidad Nacional de Colombia (UNC) for the equipments and laboratories used. In addition we thank the Grupo de Química Teórica of UNC, especially Prof. Edgar Daza for facilitating the MM+ and CODESSA calculations. Finally, we thank Prof. Isabel C. Perilla of UNC for reviewing the language of the English manuscript.

\section{References}

1. Korolkovas, A.; Essentials of Medicinal Chemistry, $2^{\text {nd }}$ ed., John Wiley \& Sons, Inc.: New York, 1988, p. 699; Petri, W.A. In Goodman \& Gilman. The Pharmacological Basis of Therapeutics ; $10^{\text {th }}$ ed., Hardman, J.G.; Limbird, L.E.; Gilman, A.G., eds.; McGraw-Hill: New York, 2001, p. 1171.

2. Quigley, J.M.; Fahelelbom, K.M.; Timoney, R.F.; Corrigan, O.I.; Int. J. Pharm. 1990, 58, 107.

3. Mauger, J.W.; Paruta, A.N.; Gerraugthty, R.J.; J. Pharm. Sci. 1972, 61, 94; Mauger, J.W.; Petersen, H.; Alexander, K.S.; Paruta, A.N.; Drug Dev. Ind. Pharm. 1977, 3, 163; Mauger, J.W.; Breon, T.L.; Petersen, H.; Paruta, A.N.; Drug Dev. Ind. Pharm. 1977, 3, 351.

4. Regosz, A.; Pelplinska, T.; Kowalsky, P.; Thiel, Z.; Int. J. Pharm. 1992, 88, 437.

5. Martínez, F.; Gómez, A.; J. Solution Chem. 2001, 30, 909.

6. Sangster, J.; Octanol-Water Partition Coefficients: Fundamentals and Physical Chemistry, John Wiley \& Sons, Inc.: Chichester, 1997, p. 43.

7. Martínez, F.; Ph.D. Thesis, Universidad Nacional de Colombia, Bogotá, Colombia, 2001.

8. USP23-NF18: The United States Pharmacopeia and the National Formulary, The United States Pharmacopeial Convention, Inc.: Rockville, 1994, p. 1449.

9. McCauley, S.A.; Brittain, H.G. In Physical Characterization of Pharmaceutical Solids ; Brittain, H.G., ed.; Marcel Dekker, Inc.: New York, 1995, p. 223.

10. Bratton, A.C.; Marshall, E.K.; Babbitt, D.; Hendrickson, A.R.; J. Biol. Chem. 1939, 128, 537.

11. Prausnitz, J.M.; Lichthenthaler, R.N.; de Azevedo, E.G.; Molecular Thermodynamics of Fluid - Phase Equilibria, $2^{\text {nd }}$ ed. Prentice-Hall: Englewood Cliffs, N.J., 1986, p. 420; Kristl, A.; Vesnaver, G.; J. Chem. Soc., Faraday Trans. 1995, 91, 995.
12. Moffat, A.C.; Jackson, J.V.; Moss, M.S.; Widdop, B.; Clarke's Isolation and Identification of Drugs, in Pharmaceuticals, Body Fluids, and Post-Mortem Material, $2^{\text {nd }}$ ed., The Pharmaceutical Press: London, 1986, p. 979; Budavari, S.; O’Neil, M.J.; Smith, A.; Heckelman, P.E.; The Merck Index, an Encyclopedia of Chemicals, Drugs, and Biologicals, $11^{\text {th }} \mathrm{ed}$., Merck \& Co., Inc.: Rahway, NJ, 1989, p. 1151.

13. Yang, S.S.; Guillory, J.K.; J. Pharm. Sci. 1972, 61, 26.

14. Sunwoo, C.; Eisen, H.; J. Pharm. Sci. 1971, 60, 238.

15. Maury, L.; Rambaud, J.; Pauvert, B.; Berge, G.; Lasserre, Y.; Audran, M.; Farmaco Ed. Prat. 1986, 41, 25.

16. Martin, A.N.; Bustamante, P.; Chun, A.H.C.; Physical Pharmacy: Physical Chemical Principles in the Pharmaceutical Sciences, $4^{\text {th }}$ ed., Lea \& Febiger: Philadelphia, 1993, p. 221; Smith, M.B.; March, J.; March's Advanced Organic Chemistry, $5^{\text {th }}$ ed., John Wiley \& Sons, Inc.: New York, 2001, p. 98.

17. Martínez, F.; Gómez, A.; Ávila, C.M.; Acta Farm. Bonaerense 2002, 21, 107

18. Martin, A.; Bustamante, P.; Anal. Real Acad. Farm. 1989, 55, 175.

19. Amidon, G.L.; Anik, S.T.; J. Pharm. Sci. 1976, 65, 801; Valvani, S.C.; Yalkowsky, S.H.; Amidon, G.L.; J. Phys. Chem. 1976, 80, 829; Leahy, D.E.; J. Pharm. Sci. 1986, 75, 629; Regosz, A.; Wojtkiewicz, T.; Osmialowsky, K.; Kaliszan, R.; Acta Pharm. Jugosl. 1991, 41, 4.

20. Katritzky, A.; Lovanov, V.; Karelson, M.; CODESSA: Comprehensive Descriptors for Structural and Statistical Analysis, Version 2.13 (PC), SemiChem and the University of Florida, 1995.

21. Bondi, A.; J. Phys. Chem. 1964, 68, 441; Edward, J.T.; J. Chem. Educ. 1970, 47, 261.

22. Schoemaker, D.P.; Garland, G.W.; Experimentos de Fisicoquímica, Unión Tipográfica Editorial Hispano Americana: México, 1968, p. 43; Bevington, P.R.; Data Reduction and Error Analysis for the Physical Sciences, McGraw-Hill Book Co.: New York, 1969, p. 56

23. Kristl, A.; Vesnaver, G.; J. Chem. Soc., Faraday Trans. 1995, 91, 995.

24. Valvani, S.C.; Yalkowsky, S.H. In Physical Chemical Properties of Drugs ; Yalkowsky, S.H.; Sinkula, A.A.; Valvani, S.C., eds.; Marcel Dekker, Inc: New York, 1980, ch. 6, p. 201; Yalkowsky, S.H.; Valvani, S.C.; Roseman, T.J.; J. Pharm. Sci. 1983, 72, 866

25. Seiler, P.; Eur. J. Med. Chem. -Chim. Therap. 1974, 9, 473.

Received: July 22, 2002 Published on the web: September 10, 2003 